\title{
Optimal Replenishment Strategy under Combined Criteria
}

\author{
P. K. Tripathy ${ }^{1}$, Bhabani S. Mohanty ${ }^{2 *}$ \\ ${ }^{1}$ P. G. Dep. of Statistics, Utkal University, Bhubaneswar-751004, India \\ ${ }^{2}$ Srusti Academy of Management, Bhubaneswar-751024, India \\ *Corresponding Author: bhabanishankar88@gmail.com, Tel.:9040630364
}

Available online at: www.isroset.org

Accepted 13/Aug/2018, Online 30/Aug/2018

\begin{abstract}
This article focuses on determining an optimal replenishment policy for items with three-parameter Weibull distribution deterioration where it represents the time to deterioration of a product. It is also observed that the demand of a consumer product usually varies with its cost and hence, the demand rate should be taken as price dependent. Holding cost is a linear function of time. Here replenishment strategy is developed under combined criteria of demand, deterioration and holding cost. The applicability of the model lies in the management of inventories of deteriorating products and for the particular items for which demand falls due to increase of its cost. Numerical illustrations and sensitivity analysis are provided to illuminate the effect of change of model parameters.
\end{abstract}

Keywords: Weibull Distribution, Time-varying Holding Cost, Price Dependent Demand, Deterioration

AMS Subject Classification No: 90B05

\section{Introduction}

Inventory management for deteriorating items is very challenging task in all types of business and making proper inventory decision is a key factor of success. Deterioration makes product demand and value dull. So it is a trending research area for all the researchers of inventory area. Deterioration makes product demand and value dull.

The instantaneous rate of deterioration of inventory at time $t$ is defined by $\theta(t)=\alpha \beta(t-\gamma)^{\beta-1}$, where $\gamma$ is the location parameter, $t \geq \gamma ; \alpha$ is the scale parameter and $\beta$ is the shape parameter; $\alpha>0, \beta>0 \& \gamma>0$ represents the three-parameter Weibull Distribution deterioration rate at any time $t>0$. Three parameter Weibull distribution is applicable for items with any initial value of rate of deterioration and which start deterioration only after a definite period of time. 


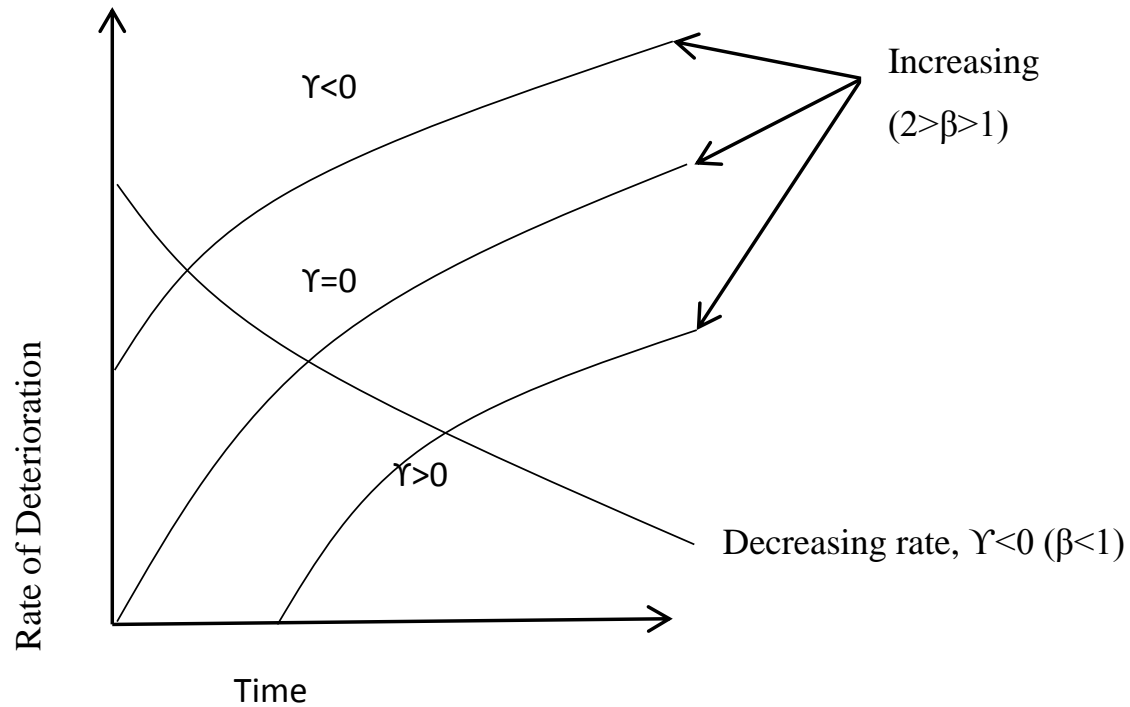

Figure 1 : Rate of deterioration and time relationship for three-parameter Weibull distribution

Ghare and Schrader [11] considered the inventory model for exponentially decaying inventory. Covert and Philip [13] obtained an inventory model for deteriorating items by taking the two-parameter Weibull distribution deterioration with constant demand and holding cost. Philip [3] developed a generalised inventory model of a three-parameter Weibull distribution deterioration and constant demand. Jalan et al. [1] and Chakrabarty et al. [20] made an extension of model of Covert and Philip [13] and Philip [3] by including a three-parameter Weibull distribution deterioration, time-dependent demand rate and shortages in the inventory. Wu et al. [4, 5], Deng [12] derived an inventory model for deteriorating items by following the Weibull distribution with time-varying and ramp type demand respectively. Banerjee and Agrawal [14], Ghosh and chaudhuri [15], Sanni and Chukwu [19] obtained a solution for an inventory model with Weibull deterioration and various types of deterministic demand (namely, trended and time quadratic). Ghosh et al. [16] developed a production model with Weibull demand. Goyal and Giri [17], Manna and Chaudhuri [18], Sahoo and Tripathy [6] did an attempt in his paper to obtain the optimal ordering quantity of deteriorating items for time-dependent deterioration rate and demand. Tripathy and Pradhan [9] introduced a model with Weibull distribution deterioration and power demand inventory. Tripathy and Pradhan [8] developed an integrated partial backlogging inventory model having Weibull demand and variable deterioration rate. Mohanty and Tripathy [2] formulated inventory model for deteriorating items with exponentially decreasing demand under imprecise environment. Tripathy and Sukla [10] has presented interactive fuzzy inventory model with ramp type demand and Weibull deterioration. Tripathy and Bag [7] explored inventory model with default risk under conditional delay.

The work of researchers who used Weibull distribution deterioration as deterioration pattern and various form of demand with holding cost, for developing inventory models are summarized below 
Table 1. Comparison of demand pattern, deterioration and holding cost

\begin{tabular}{|c|c|c|c|}
\hline Reference & Deterioration Function & Demand Pattern & $\begin{array}{l}\text { Holding } \\
\text { Cost }\end{array}$ \\
\hline Banerjee and Agrawal [14] & $\begin{array}{l}\text { Three-parameter Weibull } \\
\text { distribution }\end{array}$ & Trended & Constant \\
\hline Chakrabarty et al. [20] & $\begin{array}{c}\text { Three-parameter Weibull } \\
\text { distribution }\end{array}$ & Trended & Constant \\
\hline Covert and Philip [13] & $\begin{array}{l}\text { Two-parameter Weibull } \\
\text { distribution }\end{array}$ & Constant & Constant \\
\hline P. S. Deng [12] & $\begin{array}{c}\text { Two-parameter Weibull } \\
\text { distribution }\end{array}$ & Ramp type & Constant \\
\hline Ghosh and Chaudhury [15] & $\begin{array}{c}\text { Two-parameter Weibull } \\
\text { distribution }\end{array}$ & Time-Quadratic & Constant \\
\hline Jalan et al. [1] & $\begin{array}{c}\text { Three-parameter Weibull } \\
\text { distribution }\end{array}$ & Trended & Constant \\
\hline G. C. Philip [3] & $\begin{array}{c}\text { Two-parameter Weibull } \\
\text { distribution }\end{array}$ & Constant & Constant \\
\hline Sahoo and Tripathy [6] & $\begin{array}{l}\text { Three-parameter Weibull } \\
\text { distribution }\end{array}$ & Trended & Time-Quadratic \\
\hline Sanni and Chukwu [19] & $\begin{array}{l}\text { Three-parameter Weibull } \\
\text { distribution }\end{array}$ & Time-Quadratic & Constant \\
\hline K. S. Wu [5] & $\begin{array}{c}\text { Two-parameter Weibull } \\
\text { distribution }\end{array}$ & Time-Varying & Constant \\
\hline Kun -Shan Wu [4] & $\begin{array}{c}\text { Two-parameter Weibull } \\
\text { distribution }\end{array}$ & Ramp type & Constant \\
\hline Present Study & $\begin{array}{c}\text { Three-parameter Weibull } \\
\text { distribution }\end{array}$ & Price dependent & Time-Varying \\
\hline
\end{tabular}

The current study focuses on a certain kind of demand pattern where demands of the products are dependent upon its selling price. This inventory model is applicable for deteriorating items and assumes that deterioration follows a three-parameter Weibull distribution. The unique advantage of the functional form of Weibull distribution accommodates with both increasing and decreasing deterioration. Holding cost is also time-varying. An analytical solution of the model is betalked and illustrated with the help of several numerical illustrations and sensitivity of the optimal solution is also examined. 


\section{Assumptions and Notations}

The model is developed with the following assumptions and notations

i. $\quad D(p)=a p^{-b}$ represents the price-dependent demand rate, where $p$ is the selling price per unit item, $a>0$ is scale parameter and $b>0$ is shape parameter.

ii. $\theta(t)=\alpha \beta(t-\gamma)^{\beta-1}$, where $\alpha>0, \beta>0 \& \gamma>0$ represents the three-parameter Weibull distribution deterioration rate at any time $t>0$.

iii. $\quad c$ is the constant purchase cost per unit item.

iv. $A$ is the ordering cost per cycle.

v. $h(t)=h+\lambda t$, where $\lambda>0$ represents the inventory holding cost per unit of item per unit time.

vi. $T$ is the total cycle length.

vii. Shortages are not allowed.

viii. $\pi$ is the profit rate.

ix. $\quad I_{1}(T)=0$, where $I_{1}(t)$ is the inventory level at any time $t$.

\section{Mathematical Model}

Let $I_{1}(t)$ be the inventory level at any time $t$ is governed by the following differential equation.

$\frac{d I_{1}(t)}{d t}=-\theta(t) I_{1}(t)-D(p), 0 \leq t \leq T$

With $I_{1}(0)=I_{0}$ and $I_{1}(T)=0$

$I_{0}$ is the initial order quantity.

The inventory gradually depletes over time due to two key factors of demand and deterioration. The first term of the right hand side of equation (1) indicates the depletion of inventory per unit time due to deterioration only, while the second term represents that due to demand only. The negative sign indicates that the inventory level decreases over time due to these two factors.

Using $\theta(t)=\alpha \beta(t-\gamma)^{\beta-1}$ and $D(p)=a p^{-b}$, the solution of the equation (1) will be

$I_{1}(t)=I_{0} \cdot e^{\alpha(-\gamma)^{\beta}} \cdot e^{-\alpha(t-\gamma)^{\beta}}-a p^{-b} \cdot e^{-\alpha(t-\gamma)^{\beta}} \int_{0}^{t} e^{\alpha(t-\gamma)^{\beta}} d t$ 
Using $I_{1}(0)=I_{0}$ and $I_{1}(T)=0$, then equation (2) becomes

$I_{1}(0)=I_{0}=a p^{-b} \cdot e^{-\alpha(-\gamma)^{\beta}} \int_{0}^{T} e^{\alpha(t-\gamma)^{\beta}} d t$

Combining equation (2) \& (3), we get

$I_{1}(t)=a p^{-b} \cdot e^{-\alpha(t-\gamma)^{\beta}} \int_{t}^{T} e^{\alpha(t-\gamma)^{\beta}} d t$

If there is no decay, the differential equation of the inventory level $I_{2}(t)$ at any time $t$ can be written as

$\frac{d I_{2}(t)}{d t}=-D(p), 0 \leq t \leq T$

with the condition $I_{2}(T)=0$

The solution of equation (5) is

$I_{2}(t)=(T-t) a p^{-b}, 0 \leq t \leq T$

$I_{1}(0)$ and $I_{1}(t)$ be the initial stock levels at time 0 and $t$ respectively, the amount of stock depleted in time $t$ due to both demand and deterioration is $I_{1}(0)-I_{1}(t)$.

Similarly when there is no decay, the amount of stock depleted in time $t$ due to demand only is $I_{2}(0)-I_{2}(t)$.

Let $Z(t)$ be the stock loss due to deterioration in time interval $[0, t]$, which is written as

$$
\begin{aligned}
Z(t)=[ & \left.I_{1}(0)-I_{1}(t)\right]-\left[I_{2}(0)-I_{2}(t)\right] \\
& =a p^{-b} \cdot e^{-\alpha(-\gamma)^{\beta}} \int_{0}^{T} e^{\alpha(t-\gamma)^{\beta}} d t-a p^{-b} \cdot e^{-\alpha(t-\gamma)^{\beta}} \int_{t}^{T} e^{\alpha(t-\gamma)^{\beta}} d t-a p^{-b} t
\end{aligned}
$$

As of now loss to the system is due to either decay or demand, the order quantity in each cycle is as follows.

$$
\begin{aligned}
Q_{T}= & Z(T)+D(p) T \\
& =a p^{-b} \cdot e^{-\alpha(-\gamma)^{\beta}} \int_{0}^{T} e^{\alpha(t-\gamma)^{\beta}} d t
\end{aligned}
$$

The total cost per cycle is

$C(T, p)=$ Ordering Cost + Purchase Cost + Holding Cost 


$$
\begin{aligned}
& A+c Q_{T}+\int_{0}^{T} h(t) I_{1}(t) d t \\
= & A+\operatorname{cap}^{-b}\left(1-\alpha(-\gamma)^{\beta}\right)\left(T+\frac{\alpha(T-\gamma)^{\beta+1}}{\beta+1}-\frac{\alpha(-\gamma)^{\beta+1}}{\beta+1}\right) \\
+ & \operatorname{hap}^{-b}\left(\frac{T^{2}}{2}-\frac{2 \alpha(T-\gamma)^{\beta+2}}{(\beta+1)(\beta+2)}+\frac{2 \alpha(-\gamma)^{\beta+2}}{(\beta+1)(\beta+2)}+\frac{\alpha T(-\gamma)^{\beta+1}}{\beta+1}+\frac{\alpha T(T-\gamma)^{\beta+1}}{\beta+1}\right) \\
+ & \left.\lambda_{a p^{-b}}-\frac{T^{3}}{6}+\frac{\alpha T^{2}(T-\gamma)^{\beta+1}}{2(\beta+1)}-\frac{3 \alpha T(T-\gamma)^{\beta+2}}{(\beta+1)(\beta+2)}+\frac{3 \alpha(T-\gamma)^{\beta+3}}{(\beta+1)(\beta+2)(\beta+3)}-\frac{3 \alpha(-\gamma)^{\beta+3}}{(\beta+1)(\beta+2)(\beta+3)}\right)
\end{aligned}
$$

Hence the average system cost is

$$
\begin{aligned}
& C^{*}(T, p)=\frac{C(T, p)}{T} \\
& =\frac{1}{T}\left[\begin{array}{l}
A+\operatorname{cap}^{-b}\left(1-\alpha(-\gamma)^{\beta}\right)\left(T+\frac{\alpha(T-\gamma)^{\beta+1}}{\beta+1}-\frac{\alpha(-\gamma)^{\beta+1}}{\beta+1}\right) \\
+\operatorname{hap}^{-b}\left(\frac{T^{2}}{2}-\frac{2 \alpha(T-\gamma)^{\beta+2}}{(\beta+1)(\beta+2)}+\frac{2 \alpha(-\gamma)^{\beta+2}}{(\beta+1)(\beta+2)}+\frac{\alpha T(-\gamma)^{\beta+1}}{\beta+1}+\frac{\alpha T(T-\gamma)^{\beta+1}}{\beta+1}\right) \\
+\lambda a p^{-b}\left(\frac{T^{3}}{6}+\frac{\alpha T^{2}(T-\gamma)^{\beta+1}}{2(\beta+1)}-\frac{3 \alpha T(T-\gamma)^{\beta+2}}{(\beta+1)(\beta+2)}+\frac{3 \alpha(T-\gamma)^{\beta+3}}{(\beta+1)(\beta+2)(\beta+3)}-\frac{3 \alpha(-\gamma)^{\beta+3}}{(\beta+1)(\beta+2)(\beta+3)}\right)
\end{array}\right]
\end{aligned}
$$

Now profit can be written as a function of the cycle length and price as given below

$$
\begin{aligned}
& \pi(T, p)=p D(p)-C^{*}(T, p) \\
& =a p^{1-b}-\frac{1}{T}\left[\begin{array}{l}
A+\operatorname{cap}^{-b}\left(1-\alpha(-\gamma)^{\beta}\right)\left(T+\frac{\alpha(T-\gamma)^{\beta+1}}{\beta+1}-\frac{\alpha(-\gamma)^{\beta+1}}{\beta+1}\right) \\
+\operatorname{hap}^{-b}\left(\frac{T^{2}}{2}-\frac{2 \alpha(T-\gamma)^{\beta+2}}{(\beta+1)(\beta+2)}+\frac{2 \alpha(-\gamma)^{\beta+2}}{(\beta+1)(\beta+2)}+\frac{\alpha T(-\gamma)^{\beta+1}}{\beta+1}+\frac{\alpha T(T-\gamma)^{\beta+1}}{\beta+1}\right) \\
+\lambda a p^{-b}\left(\frac{T^{3}}{6}+\frac{\alpha T^{2}(T-\gamma)^{\beta+1}}{2(\beta+1)}-\frac{3 \alpha T(T-\gamma)^{\beta+2}}{(\beta+1)(\beta+2)}+\frac{3 \alpha(T-\gamma)^{\beta+3}}{(\beta+1)(\beta+2)(\beta+3)}-\frac{3 \alpha(-\gamma)^{\beta+3}}{(\beta+1)(\beta+2)(\beta+3)}\right)
\end{array}\right)
\end{aligned}
$$

Our aim is to determine the values of $\mathrm{T}$ and $\mathrm{p}$ that minimize the $C^{*}(T, p)$ and maximize the $\pi(T, p)$

Now $\frac{\partial C^{*}(T, p)}{\partial T}=0$

$$
\frac{\partial C^{*}(T, p)}{\partial T}=\frac{1}{T}\left[\begin{array}{l}
\operatorname{cap}^{-b}\left(1-\alpha(-\gamma)^{\beta}\right)\left(1+\alpha(T-\gamma)^{\beta}\right) \\
+\operatorname{hap}^{-b}\left(T-\frac{2 \alpha(T-\gamma)^{\beta+1}}{\beta+1}+\frac{\alpha(-\gamma)^{\beta+1}}{\beta+1}+\frac{\alpha(T-\gamma)^{\beta+1}}{\beta+1}+\alpha T(T-\gamma)^{\beta}\right) \\
+\lambda a p^{-b}\left(\frac{T^{2}}{2}+\frac{\alpha T(T-\gamma)^{\beta+1}}{(\beta+1)}+\frac{\alpha T^{2}(T-\gamma)^{\beta}}{2}-\frac{3 \alpha(T-\gamma)^{\beta+2}}{(\beta+1)(\beta+2)}-\frac{3 \alpha T(T-\gamma)^{\beta+1}}{\beta+1}+\frac{3 \alpha(T-\gamma)^{\beta+2}}{(\beta+1)(\beta+2)}\right)-C^{*}(T, p)
\end{array}\right]
$$

$\&$

$\frac{\partial \pi(T, p)}{\partial p}=0$ 
$\frac{\partial \pi(T, p)}{\partial p}=a(1-b) p^{-b}+\frac{1}{T}\left[\begin{array}{l}c a b p^{-b-1}\left(1-\alpha(-\gamma)^{\beta}\right)\left(T+\frac{\alpha(T-\gamma)^{\beta+1}}{\beta+1}-\frac{\alpha(-\gamma)^{\beta+1}}{\beta+1}\right) \\ +h a b p^{-b-1}\left(\frac{T^{2}}{2}-\frac{2 \alpha(T-\gamma)^{\beta+2}}{(\beta+1)(\beta+2)}+\frac{2 \alpha(-\gamma)^{\beta+2}}{(\beta+1)(\beta+2)}+\frac{\alpha T(-\gamma)^{\beta+1}}{\beta+1}+\frac{\alpha T(T-\gamma)^{\beta+1}}{\beta+1}\right) \\ +\lambda a b p^{-b-1}\left(\frac{T^{3}}{6}+\frac{\alpha T^{2}(T-\gamma)^{\beta+1}}{2(\beta+1)}-\frac{3 \alpha T(T-\gamma)^{\beta+2}}{(\beta+1)(\beta+2)}+\frac{3 \alpha(T-\gamma)^{\beta+3}}{(\beta+1)(\beta+2)(\beta+3)}-\frac{3 \alpha(-\gamma)^{\beta+3}}{(\beta+1)(\beta+2)(\beta+3)}\right)\end{array}\right)$

Also

$$
\left.\begin{array}{l}
\frac{\partial C^{*}(T, p)}{\partial p}=0 \\
\frac{\partial C^{*}(T, p)}{\partial p}=-\frac{1}{T}\left[\begin{array}{l}
c a b p^{-b-1}\left(1-\alpha(-\gamma)^{\beta}\right)\left(T+\frac{\alpha(T-\gamma)^{\beta+1}}{\beta+1}-\frac{\alpha(-\gamma)^{\beta+1}}{\beta+1}\right) \\
+h a b p^{-b-1}\left(\frac{T^{2}}{2}-\frac{2 \alpha(T-\gamma)^{\beta+2}}{(\beta+1)(\beta+2)}+\frac{2 \alpha(-\gamma)^{\beta+2}}{(\beta+1)(\beta+2)}+\frac{\alpha T(-\gamma)^{\beta+1}}{\beta+1}+\frac{\alpha T(T-\gamma)^{\beta+1}}{\beta+1}\right) \\
+\lambda a b p^{-b-1}\left(\frac{T^{3}}{6}+\frac{\alpha T^{2}(T-\gamma)^{\beta+1}}{2(\beta+1)}-\frac{3 \alpha T(T-\gamma)^{\beta+2}}{(\beta+1)(\beta+2)}+\frac{3 \alpha(T-\gamma)^{\beta+3}}{(\beta+1)(\beta+2)(\beta+3)}-\frac{3 \alpha(-\gamma)^{\beta+3}}{(\beta+1)(\beta+2)(\beta+3)}\right.
\end{array}\right)
\end{array}\right]
$$

Solution of equations (12) and (13) are obtained by using Mathmatica 10.0 software to find the optimal cycle length $\mathrm{T}^{*}$ and the optimal selling price $\mathrm{p}^{*}$ when the values of parameters $\mathrm{a}, \mathrm{b}, \mathrm{c}, \mathrm{h}, \lambda, \alpha, \beta, \gamma, \mathrm{A}$ are known.

For convexity of $C^{*}(T, p)$, we must have

$$
\left|\begin{array}{ll}
\frac{\partial^{2} C^{*}(T, p)}{\partial T^{2}} & \frac{\partial^{2} C^{*}(T, p)}{\partial T \partial p} \\
\frac{\partial^{2} C^{*}(T, p)}{\partial p \partial T} & \frac{\partial^{2} C^{*}(T, p)}{\partial p^{2}}
\end{array}\right|>0
$$

\section{Numerical Illustrations \& Sensitivity Analysis}

This section presents and solves three numerical illustrations to explain how the solution procedure works in support of derived model.

The items of the product like food stuffs, photographic films and electronic devices for which demand falls with increase of its cost, that is $D(p)=a p^{-b}$ where $p$ is the selling price per unit item and $a$ and $b$ are arbitrary constants satisfying $a>0$ and $b>0$. Consider the inventory model with the following values of system parameters:

Illustration 1: $2>\beta$ and $\gamma>0$ 
Let $\mathrm{a}=100000, \mathrm{~b}=2.05, \mathrm{c}=20, \mathrm{~h}=4, \lambda=0.2, \mathrm{~A}=80, \alpha=0.4, \beta=8, \gamma=0.2$. The optimum solution for $\mathrm{T}$ and $\mathrm{p}$ of equation (12) are $\mathrm{T}=0.853778$ and $\mathrm{p}=42.4797$. Putting the solution for $\mathrm{T}$ and $\mathrm{p}$ of equation (12) in equation (10) and (11), $C^{*}(T, p)=1093.34$ and $\pi(T, p)=858.34$

Illustration 2: $\beta<1$ and $\gamma<0$

Let $\mathrm{a}=100000, \mathrm{~b}=2.05, \mathrm{c}=20, \mathrm{~h}=4, \lambda=0.2, \mathrm{~A}=80, \alpha=0.4, \beta=0.7, \gamma=-4$. The optimum solution for $\mathrm{T}$ and $\mathrm{p}$ of equation (12) are $\mathrm{T}=12.1150$ and $\mathrm{p}=21.1016$. Putting the solution for $\mathrm{T}$ and $\mathrm{p}$ of equation (12) in equation (10) and (11), $C^{*}(T, p)=2090.63$ and $\pi(T, p)=1978.19$

Illustration 3: $2>\beta>1$ and $\gamma<0$

Let $\mathrm{a}=100000, \mathrm{~b}=2.05, \mathrm{c}=20, \mathrm{~h}=4, \lambda=0.2, \mathrm{~A}=80, \alpha=0.4, \beta=1.8, \gamma=-0.1$. The optimum solution for $\mathrm{T}$ and $\mathrm{p}$ of equation (12) are $\mathrm{T}=0.550518$ and $\mathrm{p}=44.1007$. Putting the solution for $\mathrm{T}$ and $\mathrm{p}$ of equation $(12)$ in equation $(10)$ and $(11), C^{*}(T, p)=1106.41$ and $\pi(T, p)=770.02$

Illustration 4: $2>\beta>1$ and $\gamma=0$

Let $\mathrm{a}=100000, \mathrm{~b}=2.05, \mathrm{c}=20, \mathrm{~h}=4, \lambda=0.2, \mathrm{~A}=80, \alpha=0.4, \beta=1.8, \gamma=0$. The optimum solution for $\mathrm{T}$ and $\mathrm{p}$ of equation (12) are $\mathrm{T}=0.57078$ and $\mathrm{p}=43.4397$. Putting the solution for $\mathrm{T}$ and $\mathrm{p}$ of equation (12) in equation $(10)$ and $(11), C^{*}(T, p)=1116.62$ and $\pi(T, p)=789.80$

Illustration 5: $2>\beta>1$ and $\gamma>0$

Let $\mathrm{a}=100000, \mathrm{~b}=2.05, \mathrm{c}=20, \mathrm{~h}=4, \lambda=0.2, \mathrm{~A}=80, \alpha=0.4, \beta=1, \gamma=0.1$. The optimum solution for $\mathrm{T}$ and $\mathrm{p}$ of equation (12) are $\mathrm{T}=27.4500$ and $\mathrm{p}=412.4938$. Putting the solution for $\mathrm{T}$ and $\mathrm{p}$ of equation $(12)$ in equation $(10)$ and $(11), C^{*}(T, p)=94.7999$ and $\pi(T, p)=84.5956$

Next, the effects of changes of model parameters are studied on the minimum average total cost per unit time and optimum profit. The sensitivity analysis is performed by changing each of parameters by $+50 \%,+25 \%,-25 \%$ and $-50 \%$ taking one parameter at a time while considering remaining parameters unchanged. The results are used in numerical illustration 1 and listed in table 2. 
Table 2. Sensitivity analysis by changing model parameters

\begin{tabular}{|c|c|c|c|c|c|c|c|}
\hline $\begin{array}{l}\text { Param } \\
\text { eters }\end{array}$ & $\begin{array}{l}\% \text { change in } \\
\text { parameter }\end{array}$ & $T$ & $p$ & $C^{*}(T, p)$ & $\begin{array}{l}\text { Relative Change } \\
\text { of Error (\%) For } \\
C^{*}(T, p)\end{array}$ & $\pi(T, p)$ & $\begin{array}{l}\text { Relative Change of } \\
\text { Error }(\%) \text { For } \\
\pi(T, p)\end{array}$ \\
\hline \multirow[t]{4}{*}{$\mathrm{a}$} & +50 & 0.730337 & 41.943 & 1629.16 & 49.0076 & 1337.72 & 55.9114 \\
\hline & +25 & 0.788908 & 42.1899 & 1359.97 & 24.3867 & 1097.23 & 27.8316 \\
\hline & -25 & 0.924328 & 42.8318 & 829.812 & -24.1030 & 621.319 & -27.6139 \\
\hline & -50 & 1.0052 & 43.3262 & 569.159 & -47.9431 & 386.674 & -54.9510 \\
\hline \multirow[t]{4}{*}{$\mathrm{b}$} & +50 & 1.43817 & 41.7934 & 84.8256 & -92.2416 & -41.5541 & -104.8412 \\
\hline & +25 & 1.13657 & 37.4471 & 282.561 & -74.1562 & 65.4031 & -92.3803 \\
\hline & -25 & 0.461206 & 59.8681 & 4048.9 & 270.3240 & 7036.66 & 719.7987 \\
\hline & -50 & 0.633744 & 872.55 & 2185.42 & 99.8848 & 8224.14 & 858.1448 \\
\hline \multirow[t]{4}{*}{$\mathrm{c}$} & +50 & 0.990718 & 62.8571 & 743.215 & -32.0234 & 550.17 & -35.9030 \\
\hline & +25 & 0.940561 & 52.7141 & 881.972 & -19.3323 & 673.911 & -21.4867 \\
\hline & -25 & 0.685135 & 31.9948 & 1462.94 & 33.8047 & 1165.31 & 35.7632 \\
\hline & -50 & 0.456837 & 21.3212 & 2236.62 & 104.5677 & 1788.21 & 108.3335 \\
\hline \multirow[t]{4}{*}{$\mathrm{h}$} & +50 & 0.760958 & 43.5573 & 1078.82 & -1.3280 & 822.194 & -4.2112 \\
\hline & +25 & 0.806533 & 43.0546 & 1102.87 & 0.8716 & 821.464 & -4.2962 \\
\hline & -25 & 0.899443 & 41.8206 & 1105.14 & 1.0793 & 878.858 & 2.3904 \\
\hline & -50 & 0.94142 & 41.0783 & 1120.46 & 2.4805 & 901.196 & 4.9929 \\
\hline \multirow[t]{4}{*}{$\lambda$} & +50 & 0.850832 & 42.4896 & 1093.42 & 0.0073 & 857.783 & -0.0649 \\
\hline & +25 & 0.852304 & 42.4847 & 1093.38 & 0.0037 & 858.061 & -0.0325 \\
\hline & -25 & 0.855213 & 42.4746 & 1093.31 & -0.0027 & 858.62 & 0.0326 \\
\hline & -50 & 0.856731 & 42.4696 & 1093.27 & -0.0064 & 858.902 & 0.0655 \\
\hline \multirow[t]{4}{*}{ A } & +50 & 0.949628 & 42.9731 & 1113.96 & 1.8860 & 819.201 & -4.5598 \\
\hline & +25 & 0.909666 & 42.7541 & 1102.84 & 0.8689 & 835.695 & -2.6382 \\
\hline & -25 & 0.768605 & 42.1031 & 1087.1 & -0.5707 & 882.92 & 2.8637 \\
\hline & -50 & 0.635758 & 41.5581 & 1085.85 & -0.6851 & 911.305 & 6.1706 \\
\hline \multirow[t]{4}{*}{$\alpha$} & +50 & 0.838117 & 42.4283 & 1096.37 & 0.2771 & 857.801 & -0.0628 \\
\hline & +25 & 0.845328 & 42.4519 & 1094.97 & 0.1491 & 858.057 & -0.0330 \\
\hline & -25 & 0.863995 & 42.5133 & 1091.41 & -0.1765 & 858.658 & 0.0370 \\
\hline & -50 & 0.876948 & 42.5559 & 1088.99 & -0.3979 & 859.025 & 0.0798 \\
\hline \multirow[t]{4}{*}{$\beta$} & +50 & 0.895386 & 42.6099 & 1085.78 & -0.6915 & 859.639 & 0.1513 \\
\hline & +25 & 0.878695 & 42.5552 & 1088.83 & -0.4125 & 859.222 & 0.1028 \\
\hline & -25 & 0.81591 & 42.3802 & 1100.16 & 0.6238 & 856.339 & -0.2331 \\
\hline & -50 & 0.755085 & 42.2522 & 1111.24 & 1.6372 & 851.475 & -0.7998 \\
\hline \multirow[t]{4}{*}{$\gamma$} & +50 & 0.891276 & 42.5984 & 1086.48 & -0.6274 & 859.496 & 0.1347 \\
\hline & +25 & 0.874346 & 42.5442 & 1089.55 & -0.3466 & 859.028 & 0.0802 \\
\hline & -25 & 0.830107 & 42.4081 & 1097.79 & 0.4070 & 857.356 & -0.1146 \\
\hline & -50 & 0.803891 & 42.3325 & 1102.81 & 0.8662 & 856.0 & -0.2726 \\
\hline
\end{tabular}


On the basis of the results shown in above table, the following observations can be made.

○ $C^{*}(T, p)$ and $\pi(T, p)$ are moderately sensitive to changes in $a$.

$\circ \quad C^{*}(T, p)$ and $\pi(T, p)$ are highly sensitive to changes in $b$.

○ $C^{*}(T, p)$ and $\pi(T, p)$ are moderately sensitive to changes in $c$.

○ $C^{*}(T, p)$ and $\pi(T, p)$ are almost sensitive to changes in $h$.

○ $C^{*}(T, p)$ and $\pi(T, p)$ are all insensitive to changes in the parameter $\lambda$.

○ $C^{*}(T, p)$ and $\pi(T, p)$ are almost sensitive to changes in $A$.

○ $C^{*}(T, p)$ has low sensitivity and $\pi(T, p)$ is insensitive to changes in $\alpha$.

○ $\quad C^{*}(T, p)$ and $\pi(T, p)$ are all slightly sensitive to changes in the parameter $\beta$ and $\gamma$

The observation from above example is that the total cost function is strictly convex. Thus, the optimal value of $\mathrm{T}$ can be obtained with the help of total cost function of the model where the total cost per unit time of the inventory system is minimum.

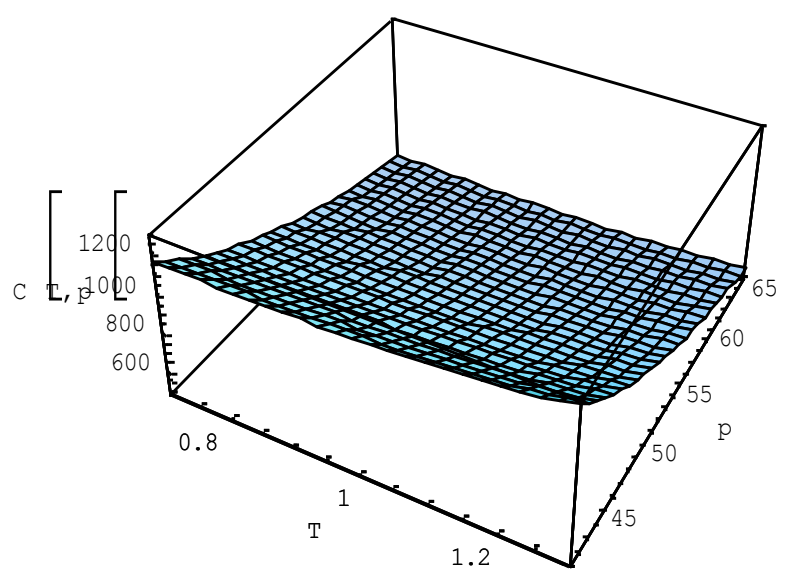

Figure 2: $C^{*}(T, p)$ vs. T and p

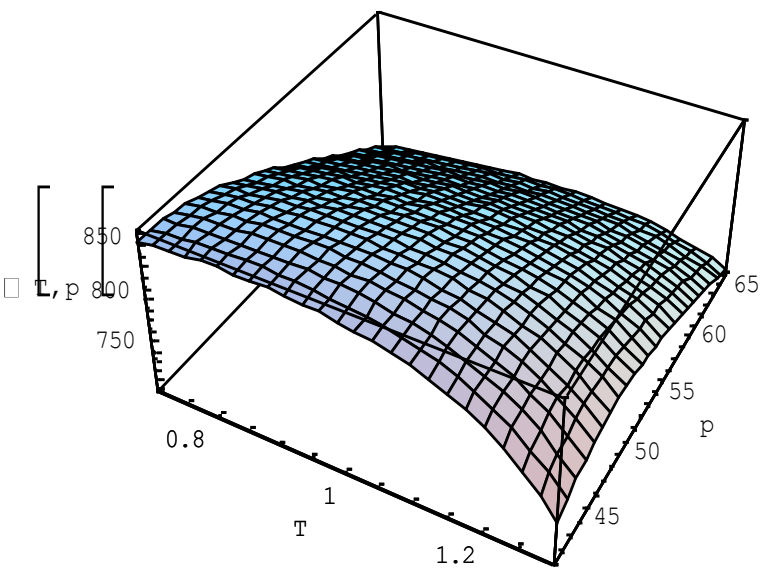

Figure 3: $\pi(T, p)$ vs. T and 


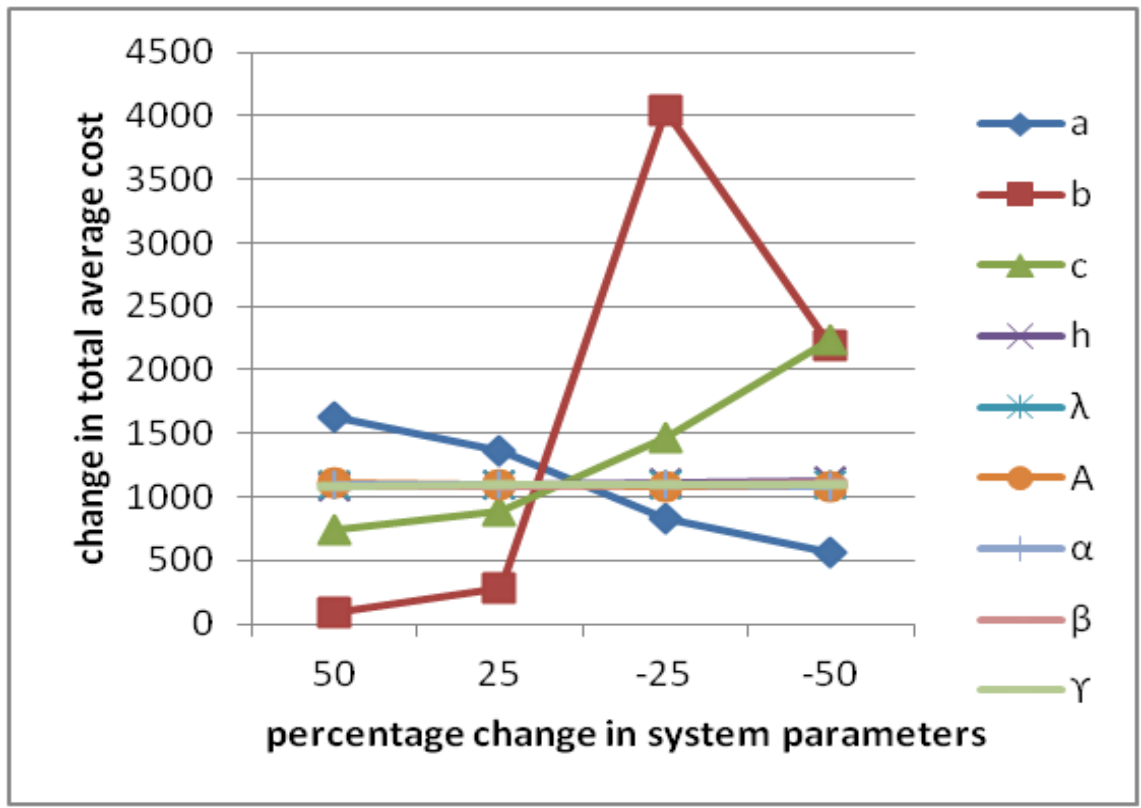

Figure 4: Change of average cost with the change of parameters

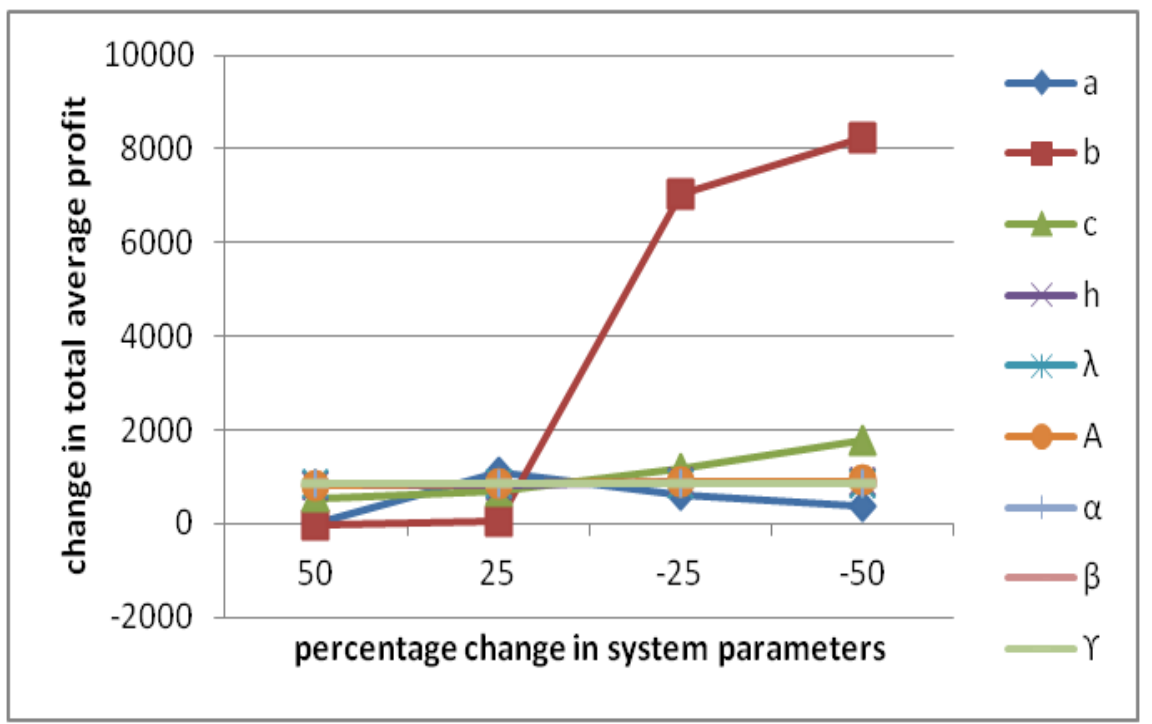

Figure 5: Change of average profit with the change of parameters

\section{CONCLUSION}

The classical economic order quantity model assumes a pre-determined constant demand rate and no effects on deterioration of items. In reality, not only demand varies with time, but also variable costs are affected by demand of product. In the proposed model, it represents a deterministic inventory model for deteriorating inventory model with three parameter weibull distribution deterioration rate and demand rate is function of selling price. The holding cost is time varying and linear function of time. 
Furthermore, three numerical illustrations are provided in support of theory. Sensitivity analysis for parameters is discussed to assess the effects of optimum solutions with the change of parameters. The derived model is suitable for items with any initial value of the rate of deterioration and also which start deteriorating only after certain period of time. In real situation, almost demands of frequently used products are dependent on selling price for which this model is quite applicable.

A future research may be considered to extend the model under stochastic demand, random or non-instantaneous deterioration and credit policy.

\section{ACKNOWLEDGMENT}

The authors express their thanks to anonymous reviewer for the fruitful suggestions to develop this work.

\section{REFERENCES}

[1] A. K. Jalan, R. R. Giri, K. S. Chaudhuri, "EOQ model for items with Weibull distribution deterioration, shortages and trend demand", International Journal of Systems Science, Vol. 27, pp. 851-855, 1996.

[2] B. S. Mohanty, P. K. Tripathy, "Fuzzy Inventory Model for Deteriorating Items with Exponentially Decreasing Demand under Fuzzified Cost and Partial Backlogging", International Journal of Mathematics Trends and Technology (IJMTT), Vol.51, Issue.3, pp.182-189, 2017.

[3] G. C. Philip, “A generalized EOQ model for items with Weibull distribution deterioration”, AIIE Transactions, Vol.6, pp.159-162, 1974.

[4] K. S. Wu, "An EOQ inventory model for items with Weibull distribution deterioration, ramp type demand rate and partial backlogging", Production Planning \& Control: The Management of operations, Vol.12, Issue.8, pp.787-793, 2001.

[5] K. S. Wu, "Deterministic inventory model for items with time varying demand, Weibull distribution deterioration and shortages", Yugoslav Journal of Operations Research, Vol.12, Issue.1, pp.61-71, 2002.

[6] N. K. Sahoo, P. K. Tripathy, “An EOQ model with three parameter weibull deterioration, trended demand and time varying holding cost with salvage”, International Journal of Mathematics Trends and Technology, Vol.51, Issue.5, pp.25-29, 2017.

[7] P. K. Tripathy, A. Bag, "Decision Support Model with Default Risk under Conditional Delay", International Journal of Scientific Research in Mathematical and Statistical Sciences, Vol.5, Issue.2, pp.40-45, 2018.

[8] P. K. Tripathy, and S. Pradhan, "Optimization of Power Demand Inventory Model with Weibull Deterioration in Discounted-Cash-Flow", International Journal of Computational Science, Vol.1, pp.243-255, 2007.

[9] P. K. Tripathy, S. Pradhan, “An Integrated Partial Backlogging Inventory Model having Weibull Demand and Variable Deterioration rate with the Effect of Trade Credit”, International Journal of Scientific \& Engineering Research, Vol.4, Issue.2, pp.1-5, 2011.

[10] P. K. Tripathy, S. Sukla, "Interactive fuzzy inventory model with ramp demand under trade credit financing", International Journal of Agricultural and Statistical Sciences, Vol.14, Issue.1, pp.377-390, 2018.

[11] P. M. Ghare, G. P. Schrader, “A model for an exponentially inventory, Journal of Industrial Engineering, Vol.14, Issue.5, pp.238-243, 1963.

[12] P. S. Deng, "Improved inventory models with ramp type demand and weibull deterioration", International Journal of Information and Management Sciences, Vol.16, Issue.4, pp.79-86, 2005.

[13] R. P. Covert, G. C. Philip, “An EOQ model for items with Weibull distribution deterioration”, AIIE Transactions, Vol. 5, pp.323-326, 1973.

[14] S. Banerjee, S. Agrawal, "A two-warehouse inventory model for items with three-parameter Weibull distribution deterioration, shortages and linear trend in demand", International Transactions in Operational Research, Vol.15, pp.755-775, 2008.

[15] S. K. Ghosh, K. S. Chaudhuri, "An order-level Inventory model for a deteriorating item with Weibull distribution deterioration, time-quadratic demand and shortages", Advanced Modeling Optimization, Vol.6, Issue.1, pp.21-35, 2004. 
[16] S. K. Ghosh, S. K. Goyal, K. S. Chaudhuri, “An inventory model with weibull demand rate, finite rate of production and shortages”, International Journal of System Science, Vol.37, Issue.14, pp.1004-1009, 2006.

[17] S. K. Goyal, B. C. Giri, "The production-inventory problem of a product with time varying demand, production and deterioration rates, European Journal of Operational Research, Vol. 147, Issue. 3, pp.549-557, 2003.

[18] S. K. Manna, K. S. Chaudhuri, "An economic order quantity model for deteriorating items with time-dependent deterioration rate, demand rate, unit production cost and shortages", International Journal of Systems Science, Vol. 32, Issue.8, pp.1003-1009, 2001.

[19] S. S. Sanni, W. I. E. Chukwu, “An inventory model with three-parameter weibull deterioration, quadratic demand rate and shortages”, American Journal of Mathematical and Management Sciences, Vol.35, Issue. 2, pp.159-170, 2016.

[20] T. Chakrabarty, B. C. Giri, K. S. Chaudhuri, “An EOQ model for items with Weibull distribution deterioration, shortages and trended demand: an extension of Philp's model”, Computer and Operations Research, Vol.7, Issue.8, pp.649-657, 1998.

\section{AUTHORS' PROFILE:}

$\boldsymbol{P}$.K .Tripathy is the senior most Professor of the P.G. Department of Statistics, Utkal University and Director of Centre for IT Education, Utkal University. He has 29 years of teaching experience at P.G. level and 27 years of research experience. He pursued M.Sc. (Statistics), Utkal University, CPS (Population Studies), IIPS, Mumbai and Ph.D. (Statistics) from Utkal University. His field of research is Operations Research. He has published 70 research papers in international/national journals. He has produced 12 Doctorates and 5 are to be awarded.

Bhabani S. Mohanty is working as assistant professor (QT) in Srusti Academy of Management (NAAC 'A' Grade Management College), Bhubaneswar. He is now pursuing his Ph.D. in P.G. Department of Statistics, Utkal University. His research interests include inventory problem, decision making, fuzzy system and optimisation.

Note: Utkal University is an A+ grade University as per NAAC and tier 1 University by the UGC. It is the oldest university of the state and the mother University of the State.

"Revised paper of the same was presented at National Seminar on "Recent advances in mathematical and applied statistics", organised by Ravenshaw University on $30^{\text {th }}$ March, 2017. 